\title{
O mito do desenvolvimento no litoral sul do Espírito Santo, Brasil
}

\author{
The myth of development in the south coast of Espírito Santo, Brazil
}

\section{Le mythe du développement de la côte du sud du Espírito Santo, Brésil}

\author{
El mito del desarrollo en el litoral sur del Espírito Santo, Brasil
}

\author{
Ana Cláudia Hebling Meira ${ }^{1}$ \\ Jalcione Almeida² \\ Recebido em 26/07/2017; revisado e aprovado em 24/09/2017; aceito em 04/10/2017 \\ DOI: http://dx.doi.org/10.20435/inter.v19i2.1665

\begin{abstract}
Resumo: Este artigo resulta de pesquisa realizada no litoral sul do Espírito Santo, Brasil, junto a comunidades de pesca artesanal diante da instalação de empreendimentos portuários para o desenvolvimento. Traz a interpretação do desenvolvimento como mito operacionalizado pelo discurso, e sugere-se seja esta a razão pela qual as ações de desenvolvimento não se traduzem em melhorias na vida das populações locais.
\end{abstract}

Palavras-chave: desenvolvimento; mito; discurso; pesca; Espírito Santo.

Abstract: This article results from research carried out in the southern coast of the state of Espírito Santo, Brazil, together with artisanal fishing communities and the installation of port development projects. It brings the interpretation of development as myth operationalized by discourse and it is suggested that this is the reason why development actions do not translate into improvements in the lives of local populations.

Keywords: development; myth; speech; fishing; Espírito Santo.

Résumé: Cet article est le résultat d'une enquête réalisée sur la côte sud de Espírito Santo, Brésil, avec les communautés de pêche artisanal, avant l'installation de projets portuaires pour le développement. II apporte l'interprétation du développement comme un mythe opérationnalisé par le discours et il est suggéré que c'est la raison pour laquelle les actions de développement ne se traduisent pas par des améliorations dans la vie des populations locales.

Mots-clés: developpement; mythe; discours; peche; Espírito Santo.

Resumen: Este artículo resulta de investigación realizada en el litoral sur de Espírito Santo, Brasil junto a comunidades de pesca artesanal ante la instalación de emprendimientos portuarios para el desarrollo. Trae la interpretación del desarrollo como mito operacionalizado por el discurso y sugiere que ésta es la razón por la cual las acciones de desarrollo no se traducen en mejoras en la vida de las poblaciones locales.

Palabras clave: desarrollo; mito; discurso; pesca; Espírito Santo.

\section{INTRODUÇÃO}

Desde o início dos anos 2000, o governo do Espírito Santo adotou o discurso novo-desenvolvimentista e vem empreendendo ações no sentido de promover o desenvolvimento visando à industrialização e à ampliação da infraestrutura para exportação e para a produção de petróleo e gás. São vários os grandes projetos de desenvolvimento de norte a sul do estado que têm sido atraídos por meio de "programas de incentivos fiscais para projetos de implantação, ampliação, expansão ou diversificação da capacidade produtiva", "projetos de revitalização de estabelecimentos paralisados", "incentivos aos setores produtivos que assumem o compromisso de aumentar a competitividade das empresas estabelecidas no Estado", "fundos para incentivos

\footnotetext{
${ }^{1}$ Universidade Federal do Espírito Santo (UFES), Vitória, Espírito Santo, Brasil.

${ }^{2}$ Universidade Federal do Rio Grande do Sul (UFRGS), Porto Alegre, Rio Grande do Sul, Brasil.
} 
financeiros para as empresas com sede no Espírito Santo", financiamentos por intermédio do Banco de Desenvolvimento do Espírito Santo (Bandes), entre outros (ESPÍRITO SANTO, s.d.).

Os empresários privados também participam da promoção do desenvolvimento. As ações que mais se destacam nesse sentido são aquelas empreendidas pelo Movimento Espírito Santo em Ação. Criado em 2003, essa iniciativa reúne empresários de vários setores da economia e tem como um de seus principais objetivos revigorar a economia estadual fortalecendo os arranjos produtivos locais para "tornar as empresas ainda mais conscientes e participativas em seu papel econômico e social" (ESPÍRITO SANTO EM AÇÃO, s.d.).

Porém, em pesquisa realizada no litoral sul do Espírito Santo, Brasil, envolvendo as comunidades de pescadores das praias de Itaipava, do Pontal e de Marobá, nos municípios de Itapemirim, Marataízes e Presidente Kennedy, respectivamente, pode-se constatar que, apesar dos projetos de desenvolvimento, existem parcelas da população que não apenas não partilham de suas "benesses", como, ao contrário, sofrem consequências degradantes que, por vezes, as impedem de continuar exercendo seu trabalho ou até mesmo são expulsas dos locais de origem. Mas o "desenvolvimento" não promete melhorar a vida das pessoas? Por que isto não ocorre?

O presente artigo tem como objetivo analisar essas questões a partir da noção de desenvolvimento como mito e da apresentação/problematização de formas de operacionalização do mito do desenvolvimento que foram observadas no litoral sul, mais especificamente nas comunidades pesqueiras mencionadas que vêm sofrendo impactos dos projetos de instalações portuárias.

Vale ainda destacar que a obtenção das informações aqui apresentadas se deu por meio de pesquisa qualitativa, realizada durante os meses de julho de 2015 e maio de 2016, utilizando-se das técnicas de geração de dados por meio da observação participante, diário de campo, entrevistas semiestruturadas, contatos informais com pescadores artesanais e análise de documentos como, por exemplo, publicações, sites de internet, documentos oficiais, notícias da imprensa, entre outros.

Este artigo traz, além desta introdução, três outras seções. Na primeira, apresenta-se a crítica ao desenvolvimentismo a partir dos anos 1970, com ênfase na interpretação do desenvolvimento como mito, religião da modernidade, ideia-força conforme propõe Rist (2008). Na segunda, analisa-se o discurso do desenvolvimento do litoral sul do Espírito Santo como um sistema de sujeição do discurso, segundo Foucault (1998), com o objetivo de demonstrar que uma das formas de operacionalizar o mito do desenvolvimento é o discurso e que este se constrói a partir de um mecanismo de controle com a finalidade de se impor como ideia-força. Por fim, propõe-se interpretar o desenvolvimento do litoral sul do Espírito Santo como mito, sugerindo, à guisa de conclusões, ser esta uma das razões pelas quais suas pretendidas "benesses" não chegam às populações locais.

\section{O DESENVOLVIMENTO COMO MITO}

Desde o final da década de 1940, o desenvolvimento vem se constituindo em ideia-força que respalda acalorados debates teóricos, ações empreendidas por agências nacionais e internacionais (estatais ou não) na esperança de superar problemas como a desigualdade e a pobreza e, embora sofra várias críticas e desgastes, "não perde a força imaginativa e poder conceitual" (RADOMSKI, 2011, p. 149). Mesmo após o fracasso de programas baseados na perspectiva da modernização social e do crescimento econômico, as teorias sobre o desenvolvimento, mais heterogêneas e plurais, ganham novos matizes através de abordagens novo-desenvolvimentistas 
como, por exemplo, a Teoria das Capacitações, de Armatya Sen (2000), o Institucionalismo Histórico, de Karl Polany (1977), e a Perspectiva Orientada aos Atores, de Norman Long (2001).

As estratégias de modernização empreendidas, principalmente, por agências nacionais e internacionais de desenvolvimento não cumpriram suas promessas de redução da pobreza e das desigualdades sociais. A crença de que, após o crescimento econômico, via implantação de grandes projetos de investimento, ocorreria uma melhor distribuição da riqueza, caiu por terra. Ao contrário, o que se verificou, de modo geral, foi o aumento da desigualdade social, do desemprego, dos conflitos fundiários e da exclusão de grupos marginalizados. Diante de evidências empíricas desses fatos, outra abordagem crítica do desenvolvimento emerge ao longo dos anos 1990, apoiada nas abordagens pós-estruturalistas da Antropologia do Desenvolvimento: o "pós-desenvolvimento". Destacam-se aqui autores como James Ferguson (1990), Arturo Escobar (2005), Aníbal Quijano (2000), Edward Said (1996), entre outros.

Dentre as perspectivas pós-estruturalistas, encontra-se também a crítica ao desenvolvimento empreendida por Gilbert Rist (2008). Esse autor retoma as proposições de Durkheim e sugere, para que seja possível uma definição sociológica do desenvolvimento, que sejam afastados os pressupostos, as noções pré-definidas, e propõe utilizar a perspectiva histórica para buscar um "padrão geral do desenvolvimento".

Esse autor parte de uma crítica às pseudodefinições de desenvolvimento que se baseiam nas imagens das condições reais de existência social (ou mundos imaginados, nas palavras do autor), em que desenvolvimento é "a expressão de um (sem dúvida geral) desejo de viver uma vida melhor" (RIST, 2008, p. 11), ou em uma grande quantidade de ações, muitas vezes conflitantes entre si, que deveriam trazer maior felicidade para um número maior de pessoas, para demonstrar que tais pseudodefinições não permitem identificar o desenvolvimento.

Isto ocorre porque, por um lado, o desenvolvimento aparece como um sentimento subjetivo que varia de indivíduo para indivíduo e, por outro, ele aparece como uma série de operações para as quais não existem provas (a priori) de que elas realmente contribuirão para alcançar o objetivo declarado. Sendo assim, o desenvolvimento não existe em lugar algum- e provavelmente nunca existirá.

“E se o 'desenvolvimento' faz parte de nossa religião moderna?", pergunta Rist (2008, p. 21). Retomando novamente Durkheim, o autor afirma que a religião é "a crença de um determinado grupo social em certas verdades indiscutíveis", que determinam o "comportamento obrigatório" de modo a reforçar a coesão social.

Para afirmar sua tese, Rist (2008) parte do princípio de que não existe sociedade que não seja baseada em crenças e tradições. Ele questiona a ideia de que a sociedade moderna seja secular e racional, afirmando que "é necessário rejeitar a 'grande divisão' entre 'tradição' e 'modernidade', a própria modernidade se encontra dentro de certa tradição" (RIST, 2008, p. 21). Embora a sociedade moderna ocidental tenha tirado das igrejas o monopólio de definir as crenças, não significa que elas não existam em outros lugares, por vezes, inclusive, em instituições seculares.

É importante enfatizar a distinção que o autor faz entre ideologia e religião, para que se torne mais clara sua tese. A ideologia, segundo Rist (2008), está aberta ao debate, permite questionamentos, enquanto as crenças sociais são uma espécie de "certeza coletiva" expressa na forma de proposições simples que as pessoas acreditam porque ouvem e porque, às vezes, são legitimadas por antigos mitos. As crenças são eficazes porque obrigam à ação aqueles que 
delas compartilham ou a agir de uma maneira particular. Mesmo se individualmente é possível questionar a validade de tal proposição, é impossível escapar às obrigações coletivas. $\mathrm{O}$ ato da crença é performativo. "De fato, a ação determinada pela crença é obrigatória, e não descansa em qualquer escolha" (RIST, 2008, p. 22).

Rist (2008) chama a atenção para o fato de que, se as crenças são religiosas, elas são transmitidas por meio de sinais e rituais e ocorrem de tal maneira que não admitem contradições. Se, durante todos esses anos da "era do desenvolvimento" ${ }^{3}$, este ainda não ocorreu, seria devido aos erros dos especialistas. O "desenvolvimento" não é questionado. ${ }^{4}$ Não há quem diga (ou poucos dizem), em público, coletivamente, na sociedade moderna, que o "desenvolvimento" é ruim, ou está errado. O "desenvolvimento" é, portanto, um mito que é operado de diversas maneiras para que perdure. Duas dessas maneiras serão discutidas a seguir.

À primeira delas referem-se os rituais, como o próprio Rist (2008) chamou a atenção. No Estado do Espírito Santo existe um ritual bastante típico, quase um modus operandi do desenvolvimento. Trata-se da criação de fóruns, eventos, palestras, cursos, espaços públicos de debates entre vários agentes da sociedade para a construção (elaboração) de planos, ou programas de desenvolvimento, que são sempre televisionados, muito divulgados pela imprensa e marcados por forte "convocação" da participação da população em geral. Assim, formam-se "redes", "conselhos", "fóruns", "agências de desenvolvimento", entre outros grupos de pessoas e instituições cujo objetivo é planejar o "desenvolvimento" do Estado.

O ritual se processa da seguinte maneira: a entidade promotora realiza um evento de "lançamento" do processo de elaboração dos planos/programas, aberto ao público e bastante divulgado pela imprensa. A partir desses eventos, formam-se grupos de trabalho cuja missão é debater a atual situação e propor ações para o "desenvolvimento" futuro. Empresários, órgãos do poder público e sociedade civil são convidados ao debate como forma de legitimar as escoIhas futuras. Em seguida, é elaborado um documento, bem diagramado e impresso, para ser distribuído aos responsáveis pelo "desenvolvimento", ou pela realização das ações propostas. Por fim, outros eventos públicos, também sempre bastante divulgados pela imprensa, são realizados para a divulgação dos planos/programas ao conjunto da sociedade. Pronto! Está lançado o "desenvolvimento" no Espírito Santo5.

Além de reafirmar o mito do desenvolvimento, essa prática comum de elaboração de planos/programas evidencia a noção de desenvolvimento como mundos imaginados, que promete uma vida melhor no futuro, desde que algumas ações sejam realizadas. A estrutura da maioria desses documentos parte de um diagnóstico da situação atual, projeta uma visão de futuro e estabelece um plano de ações que, supostamente, farão com que o futuro desejado aconteça. Isto é tão significativo que, no Espírito Santo $2025^{6}$, existe uma "Carta do Futuro" que leva a

\footnotetext{
${ }^{3}$ Desde a década de 1940.

${ }^{4}$ Aqui o "desenvolvimento" está colocado entre aspas, como faz Rist (2008), para fazer referência à crença de que o "desenvolvimento" é bom, é sempre visto como coisa boa e por isso não é questionado. Aqui não se está referindo às ações do desenvolvimento.

${ }^{5}$ Durante a pesquisa de campo, localizaram-se os seguintes documentos que foram elaborados conforme o ritual mencionado: Espírito Santo 2025; Novo PEDEAG 2007-2025; Agenda Estratégica Regional Sul 2011-2021; PRODSUL; PROEDES; Espírito Santo 2030; PEDEAG 2015-2030; Plano de Ação do Projeto Desenvolvimento Econômico Territorial; Agenda para o Desenvolvimento das Cidades Capixabas 2017-2020.

${ }^{6}$ Documento elaborado pela Secretaria de Estado de Economia e Planejamento, em conjunto com o Movimento Espírito Santo em Ação, organizado por empresários de diversos setores produtivos e patrocinado pela Petrobrás.
} 
acreditar que, se realizadas as ações presentes no plano, o Espírito Santo será da maneira como ela descreve: um lugar melhor para se viver, desenvolvido e com qualidade de vida. Trata-se, portanto, de alimentar uma crença, visto que não há garantias de que essas ações serão de fato realizadas nem tampouco de que elas tenham os resultados esperados. O desenvolvimento não existe senão como crença em um futuro melhor.

Para reforçar ainda mais a ideia de desenvolvimento como crença, verifica-se que, mesmos os agentes sociais que se opõem às ações propostas, como, por exemplo, a implantação de grandes projetos portuários, estes não questionam o desenvolvimento em $\mathrm{si}^{7}$, apenas a forma como ele está sendo proposto. Tem-se como significativas nesse sentido as falas de alguns pescadores artesanais contrários à construção dos portos que, ao serem questionados sobre o desenvolvimento, não se manifestam contra essa ideia, ao contrário, sugerem ações que, segundo seu ponto de vista, seriam o "verdadeiro" desenvolvimento. Quando é perguntado a uma pescadora da Comunidade do Pontal sobre o que significa o desenvolvimento, ela responde: "Deixar a gente pescar!", referindo-se às dificuldades que os pescadores vêm enfrentando com relação às licenças para a pesca da lagosta e à ocupação do seu principal pesqueiro pelo terminal portuário (Entrevista com pescadora da Comunidade do Pontal, em 10/03/2016, Marataízes).

Feito o mesmo questionamento a outro pescador da Comunidade do Pontal, obteve-se a seguinte resposta: "Essa boca de barra aí teria que afundar mais pra fazer um canal. Fazer um canal e botar um farol sinalizando pro pescador saber onde ele pode entrar. Outro dia um bote subiu a pedra" (Entrevista com pescador da Comunidade do Pontal, em 10/03/2016, Marataízes).

Outros pescadores também fazem referência ao desenvolvimento como melhoria das condições da pesca, como, por exemplo, melhorar a estrutura para o desembarque, ter uma fábrica de gelo, acesso ao óleo diesel subsidiado, entre outros. Alguns mencionam a necessidade de infraestrutura como creches, escolas e postos de saúde.

Esse mesmo questionamento foi feito a todos os entrevistados, e nenhum deles questiona a "necessidade de desenvolvimento". Embora para cada um o desenvolvimento possa representar ações e resultados esperados diferentes, ninguém nega o desenvolvimento em si.

Rist (2008, p. 24) afirma ainda que o "'desenvolvimento", portanto, parece ser uma crença e uma série de práticas que formam um todo, apesar das contradições entre elas". Se, por um lado, a instalação de portos ou terminais portuários representa para gestores públicos o aumento na arrecadação e crescimento econômico do município, por outro, pode significar também impactos negativos sobre os serviços de educação, saúde, saneamento, entre outros serviços públicos para os quais não há investimentos suficientes ${ }^{8}$. Por sua vez, para a maioria dos pescadores, a instalação desses empreendimentos significará o "fim da pesca", o aumento do desemprego (visto que a maioria deles não acredita que serão empregados nos novos empreendimentos porque não têm qualificação profissional) e o provável aumento da violência vinculada ao crescimento desordenado das cidades. Os empreendedores prometem qualificar

Este Planejamento Estratégico, originalmente publicado no ano de 2006, foi revisado em razão da troca de governo e, no ano 2013, um novo documento foi publicado com o título "Espírito Santo 2030: plano de desenvolvimento", que, em linhas gerais, mantém as premissas originais.

${ }^{7}$ Chama-se, para fins das análises aqui propostas, "desenvolvimento em si" o conjunto de crenças que afirmam o desenvolvimento como uma coisa boa, virtuosa, algo que vai do pior ao melhor, do menos ao mais em sentido lato (ver Almeida, 1997). Este, portanto, se diferencia das ações concretas que objetivam o desenvolvimento e dos projetos para o desenvolvimento.

${ }^{8}$ Conforme demonstram Bitencourt (2013) e Gonçalves (2012). 
os pescadores para terem condições de se empregarem, entretanto os cursos oferecidos até o presente momento ou ocorrem em períodos em que os pescadores estão no mar, ou exigem um grau de escolaridade (ensino fundamental completo) que a maioria deles não tem. Assim, é comum a oferta de cursos cujas vagas não são preenchidas.

Os exemplos acima levam a crer que o desenvolvimento do litoral sul do Espírito Santo é uma crença, um mito: "eles ${ }^{9}$ vêm aqui, falam, falam, falam e nada acontece". (Entrevista com marisqueira da Comunidade de Itaipava, 15/09/2015, Itapemirim). Essa fala dirige-se tanto aos representantes dos empreendimentos como ao poder público, que têm falado em nome do desenvolvimento, e para alguns não têm feito o desenvolvimento acontecer.

\section{O DISCURSO COMO FORMA DE OPERACIONALIZAÇÃO DO MITO DO DESENVOLVIMENTO}

A segunda maneira de operacionalizar o mito do desenvolvimento, importante de ser destacada, é a construção de narrativas, o discurso do desenvolvimento.

Para Foucault (1998), o discurso assume forma de realidade material, cuja duração não pertence àquele que fala ou escreve, que possui poderes e perigos os quais, por vezes, nem se imagina, e que pode provocar lutas, vitórias, ferimentos, dominações, sofrimentos, entre outras consequências as quais não se pode controlar.

Suponho que em toda sociedade a produção do discurso é ao mesmo tempo controlada, selecionada, organizada e redistribuída por um certo número de procedimentos que tem por função conjurar seus poderes e perigos, dominar seus acontecimentos aleatórios, esquivar sua pesada e temível materialidade. (FOUCAULT, 1998, p. 8-9).

Um dos mecanismos de controle do discurso destacados pelo autor é a exclusão. E a forma mais conhecida de exclusão em nossa sociedade é a interdição. Trata-se da limitação do discurso, pois se sabe que não se tem o direito de dizer tudo, de dizer qualquer coisa em qualquer lugar e que nem todos podem falar. As limitações do discurso revelam sua ligação com o "desejo" e o "poder".

Outro princípio de exclusão destacado pelo autor é a separação/rejeição. Trata-se do mecanismo por meio do qual alguns grupos sociais são distinguidos (ou separados) dos demais e cujo discurso deverá ser rejeitado. Foucault (1998) traz como exemplo a oposição razão e loucura em que o discurso do louco não deve ser ouvido, ele é rejeitado. Nos dias atuais, uma série de instituições cumpre o papel da separação/rejeição. Destacam-se as oposições "moderno" / "atrasado", "desenvolvido"/"subdesenvolvido", "saber científico"/ "saber popular", entre outros.

A separação historicamente construída entre verdadeiro e falso constitui-se no terceiro princípio de exclusão apontado por Foucault (1998). Trata-se do princípio da vontade de verdade, que se apoia sobre um suporte e uma distribuição institucional e tende a exercer, sobre os outros discursos um poder de coerção. Como exemplos, o autor cita o apoio que a literatura ocidental busca no natural, no verossímil e a maneira como as práticas econômicas procuram se fundamentar a partir da racionalização e da teoria da riqueza e da produção.

O autor considera esses três mecanismos de controle, interdição, separação/rejeição e vontade de verdade, como mecanismos externos ao discurso. Entretanto ele chama a atenção

9 A referência ao "eles" é comumente feita pela população local, ora se referindo ao poder público, ora aos empreendedores, conforme o contexto. Neste caso refere-se aos dois. 
para o fato de que existem também mecanismos de controle que são internos ao próprio discurso: "procedimentos que funcionam, sobretudo, a título de princípios de classificação, de ordenação, de distribuição, como se se tratasse, desta vez, de submeter outra dimensão do discurso: a do acontecimento e do acaso" (FOUCAULT, 1998, p. 21).

O comentário é o primeiro desses mecanismos citados pelo autor. Trata-se do fenômeno da repetição de narrativas que se contam e se fazem variar; coisas ditas uma vez que se conservam porque se acredita haver nelas uma riqueza ou um segredo. Foucault destaca que

[...] há um desnivelamento entre os discursos: os discursos que "se dizem" no correr dos dias e das trocas, e que passam com o ato mesmo que os pronunciou; e os discursos que estão na origem de um certo número de atos novos de fala que os retomam, os transformam ou falam deles, ou seja, os discursos que, indefinidamente, para além de sua formulação, são ditos, permanecem ditos e estão ainda por dizer. (FOUCAULT, 1998, p. 22).

O desnivelamento mencionado por Foucault desempenha, por um lado, o papel de construir indefinidamente novos discursos e, por outro, o de dizer o que estava articulado silenciosamente no texto primeiro, permitindo dizer algo além do texto mesmo por meio da repetição.

Outro mecanismo interno de controle do discurso é o da autoria. O autor é entendido aqui como princípio de agrupamento do discurso, como unidade e origem de suas significações, como aquele que escreve e inventa, limitando o discurso na forma da individualidade, do eu (FOUCAULT, 1998).

Em oposição ao princípio do comentário e do autor, a organização das disciplinas aparece como o terceiro mecanismo de controle interno do discurso. Uma vez que uma disciplina se define por um conjunto de objetos, de métodos e um corpus de proposições consideradas verdadeiras, um conjunto de regras e definições, de técnicas e instrumentos, torna-se um sistema anônimo à disposição de quem quiser se servir dele. Já as disciplinas requerem não a repetição indefinida, mas a criação constante de novas proposições.

Além disso,

Uma disciplina não é a soma de tudo o que pode ser dito de verdadeiro sobre alguma coisa; não é nem mesmo o conjunto de tudo o que pode ser aceito, a propósito de um mesmo lado, em virtude de um princípio de coerência ou sistematicidade. [...]. Há mais ainda: para pertencer a uma disciplina uma proposição deve poder inscrever-se em certo horizonte teórico. (FOUCAULT, 1998, p. 31-3).

Assim, cada disciplina, dentro de seus limites, reconhece proposições verdadeiras ou falsas e deixa de fora um conjunto de saberes populares e de crenças, experiências imediatas, temas imaginários, "monstros cuja forma muda com a história do saber" (FOUCAULT, 1998, p. 33). A disciplina é, portanto, um princípio de controle da produção do discurso.

Há ainda, conforme Foucault (1998), um terceiro conjunto de procedimentos que permitem o controle do discurso, a rarefação dos sujeitos que falam, ou seja, a limitação do número de sujeitos que falam. Quem pode falar? Nem todos os sujeitos satisfazem certas exigências ou são qualificados para entrar na ordem do discurso.

Em resumo, são três as formas de coerção do discurso: as que limitam seus poderes, as que dominam suas aparições aleatórias e as que selecionam os sujeitos que falam. Para Foucault (1998) os rituais são a forma mais superficial e visível desse sistema de restrições porque eles definem as qualificações que devem possuir os indivíduos que falam, os gestos, comportamentos, circunstâncias e todo o conjunto de signos que devem acompanhar o discurso. 
Umas das formas de discurso que interessa a este estudo em especial é a "doutrina". Para Foucault (1998), a partir da ideia de modernidade no tecido social, enquanto produção da episteme, as "doutrinas" tendem a se difundir abrangendo um grande número de indivíduos que falam e, aparentemente, a única restrição para pertencer a esse grupo é a aceitação das mesmas verdades e de regras de conformidade:

A doutrina liga os indivíduos a certos tipos de enunciação e lhes proíbe, consequentemente, todos os outros; mas ela se serve, em contrapartida, de certos tipos de enunciação para ligar indivíduos entre si e diferenciá-los, por isso mesmo, de todos os outros. A doutrina realiza uma dupla sujeição: dos sujeitos que falam aos discursos e dos discursos ao grupo, ao menos virtual, dos indivíduos que falam. (FOUCAULT, 1998, p. 43).

A ritualização da palavra, a qualificação e fixação de papéis para os sujeitos que falam e a constituição de grupos doutrinários significam, para o autor, uma distribuição e uma apropriação desigual do discurso com seus poderes e saberes, ou em outras palavras, um sistema de sujeição do discurso.

O desenvolvimento do Espírito Santo não se apresenta apenas como discurso. Mais do que isso, se constitui em um sistema de sujeição, controle, dominação. Ao considerar os elementos constitutivos do sistema de sujeição do discurso, pode-se perceber todos os seus elementos presentes no contexto empírico do desenvolvimento no litoral sul do Espírito Santo.

Considerando as diferentes formas de controle externo do discurso do desenvolvimento, verificou-se, tanto nos documentos analisados, diário de campo, como nas entrevistas realizadas com representantes do poder público e dos empreendimentos, que existem temas que não são mencionados, ou seja, passam pelo processo de interdição. São temas como, por exemplo, a perda da renda dos pescadores artesanais ${ }^{10}$; a inviabilidade da continuidade da atividade pesqueira, principalmente nos pesqueiros de camarão; a inviabilidade da coleta da aroeira (atividade que substitui a renda dos pescadores da comunidade de Marobá no inverno) porque as árvores serão derrubadas para a implantação do Porto Central; os impactos ambientais relativos, por exemplo, à poluição das águas pelos rejeitos dos navios, óleo, entre outros; o fato de que o aumento da circulação de grandes embarcações aumentará também o risco de acidentes envolvendo os pequenos barcos de pesca artesanal; a assimetria assegurada pela legislação ambiental em relação à utilização/exploração/destruição dos "recursos naturais" se considerar, por um lado, os pescadores e coletores locais e, por outro, os empreendimentos; o fato de que a população local não possui qualificação profissional para ser alocada como mão de obra nos "empreendimentos do desenvolvimento"; o fato de que a população local não tem (ou tem baixa) capacidade de investimento, nem tampouco qualificação profissional para a abertura de novos negócios de prestação de serviços aos empreendimentos que serão instalados, entre outros.

Por exemplo, o terreno onde deverá ser instalada a base de apoio logístico da C-Port Brasil Logística Offshore Ltda., na Praia da Gamboa, abrange parte das pedras onde as marisqueiras retiram o marisco. Assim que adquiriu o terreno, conforme informou uma funcionária da Colônia de Pesca, a empresa proibiu o ingresso das marisqueiras, e seu terreno passou a ser vigiado por seguranças. E, a esse respeito, o que foi dito em audiência pública dessa empresa com a população local foi o seguinte:

\footnotetext{
${ }^{10}$ Esta é mencionada nos EIA/RIMA dos três empreendimentos, entretanto tais documentos tratam a questão como se fosse possível reverter esta situação com Programas de Compensação da Atividade Pesqueira. Vale destacar que estes documentos são de circulação muito restrita à população a que se destina o "desenvolvimento".
} 
Eu participei [referindo-se à Audiência Pública]. Foi até na Associação. Aí eles falaram que não ia afetar nada, que não ia prejudicar nada, porque teve todo mundo discutindo sobre as marisqueiras. Eles falaram que não, que isso não ia atingir nada. Eu não lembro o nome dele não. Ele falou que não ia prejudicar nada. (Entrevista com marisqueira da Comunidade de Itaipava, 24/02/2016, Itapemirim).

Ao elaborar o discurso que será apresentado às comunidades, informações significativas relacionadas ao seu cotidiano simplesmente não são transmitidas ou são negadas propositadamente, num processo de interdição.

No que tange à separação/sujeição, verifica-se que, no discurso do "desenvolvimento" do Espírito Santo, não se encontram as diversas comunidades tradicionais locais (indígenas, quilombolas, agricultores, pescadores, entre outras). Para estes é oferecida apenas uma escuta simbólica, nas audiências públicas ou nas reuniões para elaboração de projetos de compensação ambiental, porque a lei obriga.

Sobre audiências públicas com representantes dos empreendimentos, apresentam-se os seguintes depoimentos:

Muitas reuniões sem nada. É aquilo que você tinha falado no início sobre as possíveis compensações pesqueiras, nada aconteceu. Só promessa, promessa, promessa e nada surgiu. (Entrevista com Técnico em Pesca, 25/02/2016, Marataízes).

Marcaram uma reunião e me chamaram em cima da hora. Uma reunião que não foi pescador homem nenhum, foram algumas mulheres que eles levaram, que não dependem da pesca e não deu voz pra gente, e segundo informações, eles enfiaram uma ideia de um projeto de uma cozinha, que a gente já tentou aqui na outra gestão e não deu certo, pra tentar compensar. Eu disse: "Não é assim". Eles têm que ver quem são os afetados e o que pode ser feito. Nem sempre o dinheiro é a compensação. Eles acabam criando um problema maior que tende a crescer. (Entrevista com pescador do Pontal, 25/02/2016, Marataízes).

Nessas reuniões que tinha ai sempre o Carlos tocava no assunto para poder indenizar o pescador, mas nunca ficou resolvido isso. (Entrevista com pescador de Marobá, 04/05/2016, Presidente Kennedy).

O que os depoimentos citados evidenciam é que os pescadores, que serão diretamente afetados pelas ações do desenvolvimento, não são escutados. Essas reuniões públicas servem apenas como mais uma forma de repetição do discurso do desenvolvimento e convencimento do que propriamente para escutar essa parcela da população.

No que tange à vontade de verdade, percebe-se claramente que o discurso do desenvolvimento no Espírito Santo, principalmente aquele mais direcionado ao litoral sul, apoia-se na afirmação de "saberes" que se pretendem verdadeiros, contra outros que não o são. Observando uma das reuniões de empreendedores com a comunidade local, reunião esta que pertencia ao programa de comunicação social que era parte constitutiva dos compromissos assumidos pela empresa em seu processo de licenciamento, registrou-se a seguinte nota em diário de campo:

Os representantes das empresas, ao se apresentarem, fazem questão de manifestar sua formação acadêmica - "eu sou engenheiro", "eu sou formado na UFES", entre outros - como se isso justificasse o fato de ele falar e os outros não, ou dele ser portador do conhecimento e outros não. (Diário de campo, 05/11/2015, Anchieta).

A vontade de verdade aqui é expressa pela ideia de que os técnico-científicos é que "sabem" sobre o desenvolvimento, por isso são eles que falam em seu nome. 
Ainda sobre as disputas em torno dos "saberes", um pescador declara o seguinte:

Como são feitas as pesquisas do pessoal da UFES? Eles perguntam aos pescadores do Estado do Espírito Santo, e a resposta está na inteligência de cada pescador que tem o conhecimento do que sabe da pesca. (Entrevista com pescador da Comunidade de Itaipava, 15/09/2015, Itapemirim).

Essa declaração marca bem a separação "conhecimento popular" versus "conhecimento científico" em uma sociedade em que este último é mais valorizado (ou se apresenta como verdade) em relação ao primeiro.

Outra declaração, anotada em diário de campo, foi a de uma funcionária da Secretaria Estadual de Desenvolvimento com a seguinte afirmação:

Nós não conseguimos entender o que as comunidades de pesca querem. Eles parecem não querer trabalhar em outra profissão, ter carteira assinada, patrão, trabalhar 40 horas por semana. Eles não aceitam as mudanças. Não sabemos o que eles querem. (Diário de Campo, 11/03/2016, Vitória).

Qual é a vontade de verdade sobre o desenvolvimento expressa nessa fala? Que para desenvolver tem que trabalhar nas profissões que o "desenvolvimento" quer, da maneira como o "desenvolvimento" acha melhor, aceitar as mudanças por ele impostas. Todas essas formas relacionadas à ideia de modernização, adoção de racionalidades econômicas típicas das sociedades capitalistas, a sujeição ao trabalho assalariado, a aceitação dos processos de industrialização, entre outras, são vistas como a representação de uma "sociedade desenvolvida"11.

Dentre as formas de controles internos ao discurso, conforme Foucault (1998), chama atenção a repetição. Desde o início dos anos 2000, no Espírito Santo, a pauta do "desenvolvimento" está sempre muito presente e, mais especificamente após a publicação, em 2006, de um de seus dispositivos mais emblemáticos, o "Espírito Santo 2025: plano de desenvolvimento", esse processo se tornou ainda mais evidente. Consideram-se importantes as proposições do grupo de empresários que integra o movimento Espírito Santo em Ação, porque eles se constituem em lideranças que passam a influenciar, significativamente, as ações do Governo do Estado e de pequenos empresários no sentido de promover o "desenvolvimento" conforme seus interesses. Considera-se esse documento emblemático, não apenas pelo seu conteúdo, que expressa as noções de "desenvolvimento" e seus objetivos para o Espírito Santo, como também pelo processo de sua elaboração marcado por uma série de reuniões públicas, com diversos representantes de diversos setores do Governo do Estado, com lideranças da sociedade civil, e sempre muito noticiado pelos meios de comunicação de massas. Momentos simbólicos como o "lançamento" desse documento, em um grande evento aberto ao público, realização de audiências públicas, encontros temáticos, além de eventos para a distribuição do documento com realização de palestras, conferências e divulgação desse plano estratégico. Assim como foi destacado no item anterior, um verdadeiro processo de ritualização da palavra, importante na construção do sistema de sujeição do discurso.

Mas qual a concepção de "desenvolvimento" expressa nesse documento? Exatamente aquela que Esteva (2000, p. 74) denomina uma constelação semântica poderosa constituída por

\footnotetext{
${ }^{11} \mathrm{O}$ desenvolvimento, enquanto um sentido ideológico, pode ser percebido em seus processos participativos que pretendem induzir a ampliação de liberdades, buscando garantir qualidade de vida e coesão social. O crescimento econômico seria um dos conteúdos deste sentido.
} 
noções como evolução, crescimento, maturação e modernização. Trata-se, portanto, de uma metáfora que prega a evolução social e econômica para formas cada vez mais perfeitas, capaz de transformar a história em um programa cujo destino passa a ser necessário e inevitável e cujo modo de produção industrial tornou-se o estágio final de um caminho unilinear.

Ao analisar as proposições para o desenvolvimento do Estado do Espírito Santo, a partir dos anos 2000, verificou-se a construção de uma narrativa que, não apenas transforma o Estado em "subdesenvolvido", sempre em comparação com seus vizinhos, Minas Gerais e Rio de Janeiro e até com outros países, como, por meio de uma visão linear, baseada nas ações de modernização, promete o combate à pobreza, a redução das desigualdades e aumento na qualidade de vida de sua população.

A seguir, destacam-se alguns trechos do documento no qual o discurso do desenvolvimento vai se apresentando como evolução, crescimento, maturação, modernização, ou uma visão de futuro melhor para todos:

Até 2025 o Espírito Santo alcançará padrões de desenvolvimento próximos aos dos países com as melhores condições de vida na atualidade. E isto não é um sonho. É um projeto viável, como bem demonstra este Plano Estratégico de Desenvolvimento.

Este Plano, construído participativamente, numa parceria Governo-Sociedade, aponta para um novo ciclo de desenvolvimento do Espírito Santo, baseado na integração competitiva, em nível nacional e internacional, de uma economia capixaba diversificada e de maior valor agregado, sustentada pelo capital humano, social e institucional de alta qualidade.

O Plano Estratégico de Desenvolvimento é essencialmente uma agenda para a construção de uma realidade com democratização das oportunidades de crescimento individual e coletivo em terras capixabas.

Os quatro grandes pilares de sustentação desse novo ciclo histórico são a erradicação da pobreza e a redução das desigualdades para ampla inclusão social; o desenvolvimento do capital humano capixaba segundo padrões internacionais de excelência; a diversificação econômica, agregação de valor à produção e adensamento das cadeias produtivas; e o desenvolvimento do capital social e a devoção absoluta à ética republicana por parte das instituições públicas.

Vamos promover uma eficaz e massiva atração de investimentos produtivos. A economia capixaba aumentará sua inserção competitiva no mercado nacional e internacional, ancorada em uma agricultura de valor agregado; em um setor terciário avançado; na cadeia produtiva do petróleo e gás; em um conjunto de arranjos produtivos locais e nos grandes empreendimentos industriais competitivos em escala planetária. (ESPÍRITO SANTO, 2006, p. 6, grifos nossos).

Ao analisar os itens grifados acima, percebe-se, claramente, a visão de desenvolvimento centrado na economia e, mais do que isso, na subordinação de outras formas de interação social aos processos econômicos. Dentre os itens claramente relacionados à ideia de crescimento econômico tem-se: "integração competitiva", "economia diversificada de maior valor agregado", "adensamento de cadeias produtivas". Destacam-se as noções de "desenvolvimento do capital humano e do capital social" como representativos do processo de subordinação de outras dinâmicas sociais à ordem econômica, visto que aí se inserem investimentos em educação para a formação de mão de obra "eficiente", com promessas de investimentos em educação e fortalecimento institucional capazes de garantir as ações de "desenvolvimento". A Figura 1 demonstra bem a visão de desenvolvimento predominante durante esse período. 


\section{Um Novo e Longo Ciclo de Desenvolvimento}

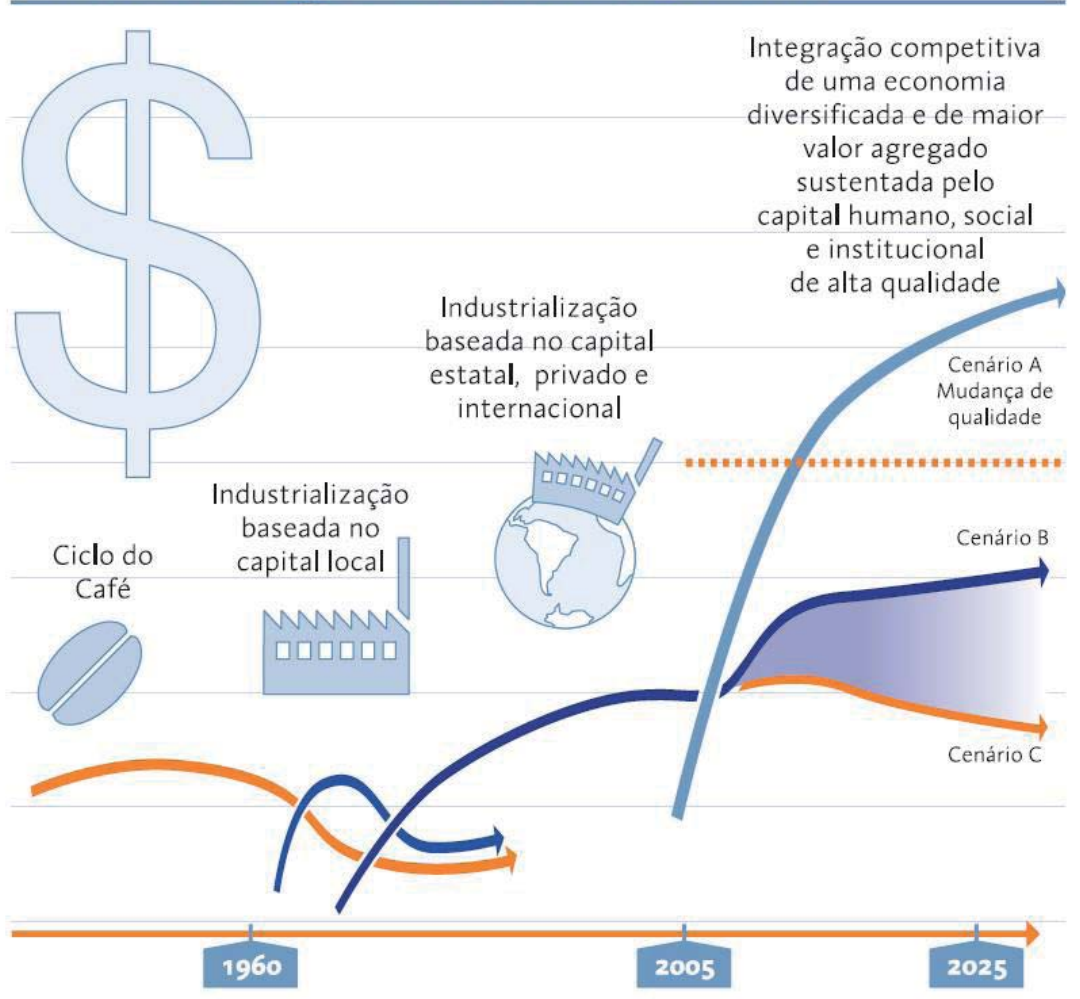

Figura 1 - Ciclos de desenvolvimento do Espírito Santo Fonte: Espírito Santo (2006, p. 47).

Além do movimento Espírito Santo em Ação, a Federação das Indústrias do Espírito Santo (FINDES) também se constitui em agente social importante na construção e divulgação da concepção de desenvolvimento predominante neste período. Analisando, por exemplo, o conteúdo publicado em sua revista Indústria Capixaba, considerando os 23 números a que se teve acesso ${ }^{12}$, 0 tema do desenvolvimento, em sua maior parte, é visto como crescimento econômico e raramente visto como desenvolvimento sustentável. Nos números analisados, a palavra "desenvolvimento" apareceu 1.556 vezes, perfazendo uma média de 68 vezes em cada número, e aproximadamente 12 matérias e/ou artigos e/ou notícias sobre o tema em cada número. Ao identificar as palavras que ocorrem com maior frequência nesses números da revista tem-se:

\footnotetext{
${ }^{12}$ A revista é bimestral e os números utilizados neste trabalho vão desde o 293, de jan./fev. 2011, ao 321, de nov./ dez. 2015. Exceções feitas para os números 308, 311, 313, 317, 318 e 320, aos quais não se teve acesso.
} 


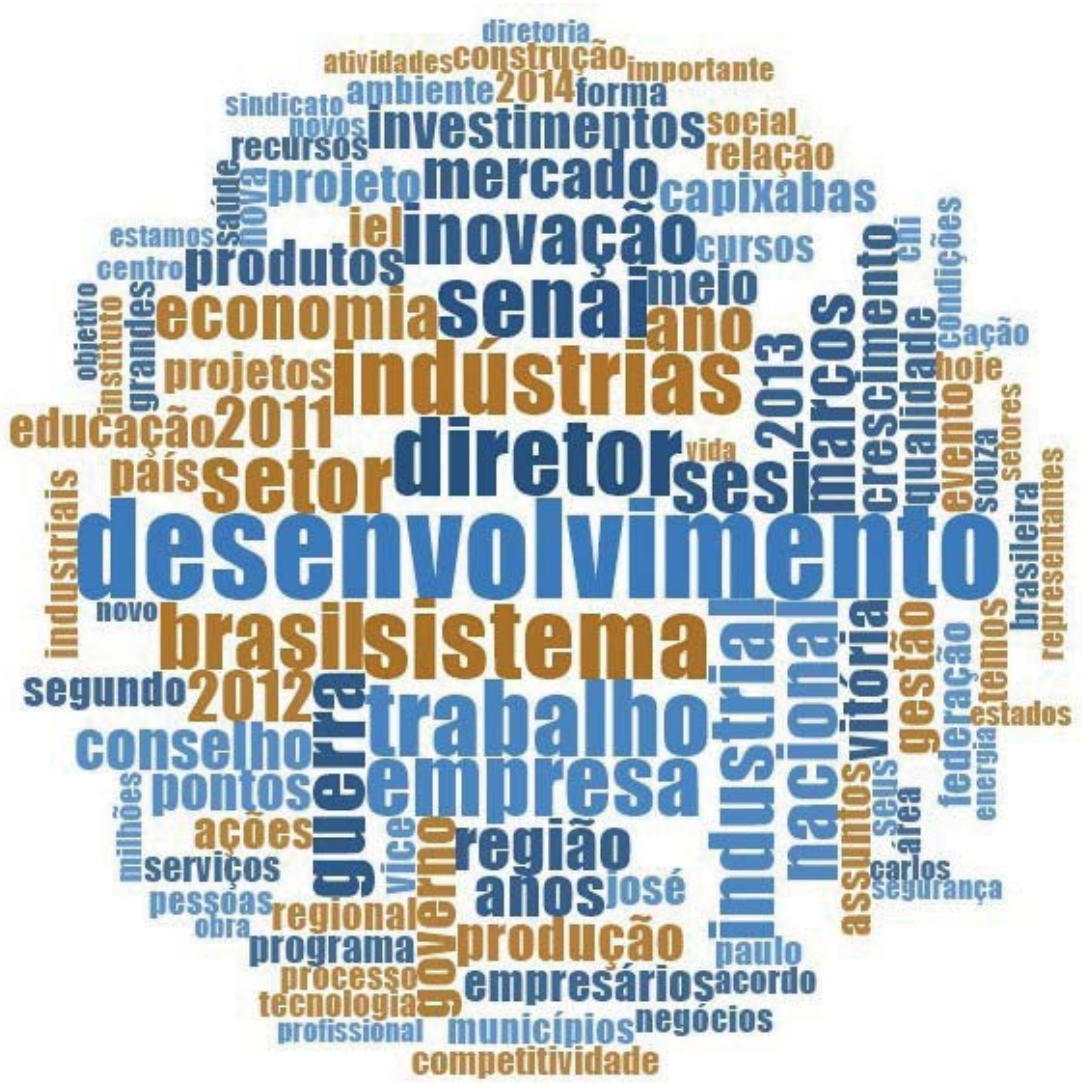

Figura 2 - Palavras mais frequentes na Revista Indústria Capixaba, de 2011 a $2015^{13}$

Fonte: Elaborado pelos autores.

Analisando as palavras que aparecem com mais frequência, evidencia-se o fato de que o "desenvolvimento", para esse veículo de comunicação que expressa a visão de mundo de parte do empresariado capixaba, em especial os industriais, está bastante relacionado à noção de desenvolvimento econômico, industrialização, modernização, pois tem-se, dentre as demais palavras, termos como trabalho, empresas, indústrias, inovação, mercado, investimentos, produtos, entre outros.

O fenômeno da repetição do discurso do "desenvolvimento" expresso claramente na Revista Indústria Capixaba pode ser também verificado nos mais variados meios de comunicação de massas, como por exemplo, a imprensa escrita, portais das redes de comunicação na internet, rádios, outras publicações locais, canais de televisão, entre outros.

Mas quem fala? Ou, quais vozes os jornalistas repercutem? Essas perguntas levam à reflexão sobre outra forma de controle do discurso que é a rarefação, ou seja, o controle dos sujeitos que falam. Por meio dos meios de comunicação de massas mencionados falam os representantes dos empreendimentos, legitimados por seus títulos acadêmicos, os representantes dos diversos setores da administração pública, estadual ou municipal, que, de alguma forma, têm relação com a "promoção do desenvolvimento", como por exemplo, o governador, os prefeitos, os secretários estaduais ou municipais de desenvolvimento, entre outros.

Já nos espaços públicos de divulgação (repetição e ritualização) do "desenvolvimento", fa-

\footnotetext{
${ }^{13}$ Antes de qualquer comentário, é necessário esclarecer que, nessa contagem de palavras frequentes, foram retiradas as palavras Estado, Espírito, Santo e Capixaba porque ocorrem com maior frequência mais em função das características da Revista (nome, localidade, público a que se destina) do que aos temas abordados.
} 
lam os técnicos especialistas, em sua maioria trabalhadores das empresas ou de órgãos públicos responsáveis pelo "desenvolvimento". Sobre essa questão, é representativa a fala de uma das lideranças das comunidades pesqueiras acerca das audiências públicas:

O Porto Central fez uma audiência pública no ginásio de esportes. Lotou com ônibus de todas as comunidades, de tudo que era canto. Botaram uma mesa de comida para um batalhão de gente comer. Aí, minha filha, foram pro microfone [representantes das empresas] e ninguém mais falou. (Entrevista com líder comunitária de Marobá, 04/05/2016, Presidente Kennedy).

Outra parte importante da formação do sistema de sujeição do discurso é a ritualização. Toma-se a forma doutrinária do discurso como exemplo. O discurso doutrinário fundamenta-se na ritualização da palavra, na qualificação e fixação de papéis e na constituição de grupos doutrinários.

Outra forma de ritualização da palavra que ocorre no Espírito Santo são os eventos. Como mencionado no item anterior, uma série de eventos de grande porte, sempre muito bem divulgados pela mídia, fazem parte dos rituais do "desenvolvimento" e proporcionam sua divulgação, disseminação e manutenção da narrativa.

\section{CONSIDERAÇÕES FINAIS}

Ao analisar o desenvolvimento no Espírito Santo, pode-se, a partir das evidências mencionadas, interpretá-lo também como discurso no sentido foucaultiano do termo, discurso como forma de operacionalizar o mito, como realidade material cuja duração, poderes e perigos os emissores do discurso nem sequer imaginam, mas que mantém, ou atualiza, o mito do "desenvolvimento" por meio do sistema de sujeição do discurso.

Sugere-se, então, que esta seja uma das razões que explicam o fato de que as comunidades locais não têm acesso às "benesses" do desenvolvimento. Precisamente porque o desenvolvimento não existe, a não ser como mito, uma crença, este mantido, divulgado, reforçado, operacionalizado por uma narrativa que afirma e reafirma a possibilidade de uma vida melhor, mas realizado por ações que, muitas vezes, submetem as populações locais a condições de vida mais precárias do que aquelas que elas tinham antes do "desenvolvimento".

\section{REFERÊNCIAS}

ALMEIDA, Jalcione. Da ideologia do progresso à ideia de desenvolvimento (rural) sustentável. In: ALMEIDA, Jalcione; NAVARRO, Zander (Org.). Reconstruindo a agricultura: ideias e ideais na perspectiva de um desenvolvimento rural sustentável. Porto Alegre: Editora da UFRGS, 1997. p. 33-55.

BITENCOURT, Christiane Provietti. Empreendimentos costeiros de grande porte e conflitos no uso e ocupação do solo: a zona costeira sul capixaba. 2013. 304f. Dissertação (Pós-Graduação em Arquitetura e Urbanismo)- Universidade Federal do Espírito Santo, Vitória, ES, 2013. 304 p.

ESCOBAR, Arturo. El "postdesarrollo" como concepto y prática social. In: Politicas de economía, ambiente y sociedad en tiempos de globalización. Caracas: Faculdad de Ciencias Económicas y Sociales, Universidad Central de Venezuela, 2005. p. 17-31.

ESPÍRITO SANTO, Estado. Espírito Santo 2025: plano de desenvolvimento. Vitória, ES: Secretaria de Estado de Economia e Planejamento, 2006. 156 p.

ESPÍRITO SANTO (Estado). Secretaria de Desenvolvimento. [s.d.]. Disponível em:<http://www.invistanoes. es.gov.br/>. Acesso em: 13 set. 2016. 
ESPÍRITO SANTO em ação. [s.d.]. Disponível em: <http://www.es-acao.org.br/index.php?id=/institucional/ espirito_santo_em_acao/index.php>. Acesso em: 13 set. 2016.

ESTEVA, Gustavo. Desenvolvimento. Dicionário do desenvolvimento. Petrópolis: Vozes, 2000. p. 59-83.

FERGUSON, James. The anti-politics machine: "development", depolitization, and bureaucratic power in Lesotho. New York: Cambridge University Press, 1990. 320p.

FOUCAULT, Michel. A ordem do discurso. 4. ed. São Paulo: Edições Loyola, 1998. 79p.

GONÇALVES, Thalismar M. Grandes projetos e mudanças no litoral capixaba: Presidente Kennedy-ES. In: ENCONTRO NACIONAL DE GEÓGRAFOS, 17., Belo Horizonte, 22-28 jul. 2012. Anais... Belo Horizonte, MG: [s.n.]. Disponível em: <http://eng2012.agb.org.br/lista-de-artigos?download=1739:trabalho-completothalismar\&start=2420>. Acesso em: 13 de set. 2014.

LONG, Norman. Development sociology: actor perspectives. London and New York: Routlege, 2001. 293p.

POLANY, Karl. Nossa obsoleta mentalidade mercantil. Revista Trimestral de História e Ideias, Porto Portugal, n. 1, p. 7-20, 1977.

QUIJANO, Aníbal. Coloniality of power, eurocentrism, and Latin America. Nepantla: views from the South, v. 1, n. 3, p. 533-80, 2000.

RADOMSKY, Guilherme F. W. Desenvolvimento, pós-estruturalismo e pós-desenvolvimento: a crítica da modernidade e a emergência de "modernidades" alternativas. Revista Brasileira de Ciências Sociais, São Paulo, v. 26, n. 75, p. 149-62, 2011.

RIST, Gilbert. The history of development: from western origins to global faith. 3. ed. London e New York: Zed Books, 2008. 288p.

SAID, Edward. Orientalismo: o Oriente como invenção do Ocidente. São Paulo: Cia das Letras, 1996. 528p. SEN, Amartya. Desenvolvimento como liberdade. São Paulo: Companhia das Letras, 2000. 416p.

\section{Sobre os autores:}

Ana Cláudia Hebling Meira: Doutora em Desenvolvimento Rural pela Universidade Federal do Rio Grande do Sul (UFRGS). Professora Adjunta lotada no Departamento de Medicina Veterinária da Universidade Federal do Espírito Santo (CCAE/UFES). Pesquisadora no grupo de Pesquisa Tecnologia, Meio Ambiente e Sociedade (TEMAS). E-mail: anameira2002@gmail.com

Jalcione Almeida: Professor e pesquisador dos Programas de Pós-Graduação em Sociologia e Desenvolvimento Rural, ambos da Universidade Federal do Rio Grande do Sul (UFRGS). Professor titular lotado no Departamento de Sociologia (IFCH/UFRGS). Pesquisador CNPq. Coordenador do grupo de Pesquisa Tecnologia, Meio Ambiente e Sociedade (TEMAS).E-mail: jal@ufrgs.br 
